\title{
The Nonexistence of Sustainability in International Maritime Shipping: Issues for Consideration
}

\author{
Chad McGuire (Corresponding author) \\ Director, Environmental Policy Certificate Program \\ Department of Public Policy, University of Massachusetts, Dartmouth \\ 285 Old Westport Road, Dartmouth, Massachusetts 02747, United States \\ Tel: 1-508-999-8520Ｅ-mail: cmcguire@umassd.edu
}

Helen Perivier

Candidate, Environmental Policy Certificate Program

Department of Public Policy, University of Massachusetts, Dartmouth

285 Old Westport Road, Dartmouth, Massachusetts, 02747, United States

Tel: 1-508-999-8520Ｅ-mail: hperivier@umassd.edu

\begin{abstract}
There is an ongoing practice in the international shipping community that impacts fundamental notions of sustainability as defined in the peer-reviewed literature (WCED, 1987; Gladwin, Kennelly \& Krause, 1995; McManus, 1996, Naess, 2003; McGregor, 2004). The practice is based in discounting the true costs of maritime shipping through a system of open registries. By engaging in such practices, there is an inherent failure by the international community to internalize the true costs (environmental, social, labor, etc.) associated with shipping. The result is a practice that artificially keeps the international costs of maritime shipping low at the expense of environmental and labor concerns. This paper will identify the methods by which this generalized unsustainable practice is carried out, and link the practices to environmental policy failures at both domestic and international scales. While the main purpose of the paper is to serve as a scoping piece to identify the unsustainable practices of the international maritime industry, some general insights are also offered to suggest research directions that may aid in ensuring our global maritime shipping industry better internalizes generally accepted principles of sustainability. Work beyond this paper should focus on in-depth analyses and case studies to further develop the general principles discussed herein.
\end{abstract}

Keywords: Sustainability, International shipping industry, Environmental impacts, Valuation

\section{Introduction}

Sustainability, at its heart, is about the internalization of costs so that we might engage in a true valuation of our actions, both today and from an intergenerational perspective (WCED, 1987). Costs, in-turn, can be measured or categorized according to a set of criteria focusing on the environmental impact of the activity. One of the most basic formulations of environmental cost was established by the ecologist Paul R. Ehrlich of Stanford University (1968). The simple equation: I (impact) $=\mathrm{P}$ (population) $\mathrm{x}$ A (affluence) $\mathrm{x} \mathrm{T}$ (technology) was meant to provide a focusing point from which environmental impact could be roughly measured. Many criticisms have developed since the publication of this original work, but the basic premise has been well defended (Ehrlich \& Ehrlich, 2009).

The basic categorization of $\mathrm{I}=\mathrm{P} \times \mathrm{A} \times \mathrm{T}$ has been refined to offer a more stringent analysis of environmental costs and benefits. One of the more generalized forms of this analysis is the Total Cost approach. In this approach, all costs of a particular action are emphasized. This is done through an evaluation of three primary categories of value: direct, indirect, and non-use. An example of total cost accounting was employed during by the Millennium Ecosystem Assessment (2005) to calculate the environmental services at-risk from human activities.

Focusing on the determination of environmental costs, we can use a total cost approach to better understand the tradeoffs involved in a particular human activity. In-turn, these tradeoffs can help us to identify actions that are impacting generally accepted sustainability goals. A conceptual model of this cost approach analysis is presented in Figure 1. Using this basic framework, we can begin to analyze the relative appropriateness of certain human activities. Applying this basic framework to international maritime shipping practices, we find established 
practices that lead to unsustainable outcomes (Note 1).

The international maritime shipping industry has continually offered low shipping costs for goods in international trade. These low shipping costs have supported an economic climate of international trade while keeping the price of goods shipped internationally artificially low. In this paper, the process by which shipping costs are kept low is highlighted, identifying the environmental consequences of this activity. Specifically, what is observed is the practices employed ultimately rely on lowered environmental standards, whether by failure to develop such standards of by a failure to enforce such standards, as a significant cost-saving measure. Thus, the environmental values are being discounted to support low-cost international trade.

This paper begins with an overview of the international shipping process, highlighting the requirements of registration. It then goes on to explain how environmental laws, both domestic and international, are being skirted through an open registry system, allowing ship owners to shop for a flag state with little to no environmental standards or enforcement. After fully explaining this process, the impacts of this practice are discussed. Finally, a number of issues are raised in order to stimulate further research and discussion on proposed solutions to this current problem.

\section{Overview of the Problem}

In 2009, some 37836 registered merchant vessels over 1000 gross tons in size moved approximately eight billion tons of seaborne trade (UNCTAD, 2009). This accounted for something between eighty to ninety-percent of the entire global trade for the year. From these basic figures alone, it is clear there is a substantial preference for maritime shipping as the primary means of global trade. In fact, the cost of shipping has been shown to be extremely low, especially when accounting for inflation. For example, bulk shipping costs have increased only about seventy-percent in the last 50 years while U.S. retail prices have risen approximately seven-hundred percent over the same period (Marisec, 2006, p. 5). Roughly translated, this suggests, in 2009 dollars, that shipping a $\$ 700$ television set from Asia to the United States costs approximately $\$ 10$ per unit. All this while the amount of freight moved (in tons per mile) has increased from 8 thousand billion ton-miles in 1968 to 32 thousand billion ton-miles in 2008, a four-fold increase over a forty year period (Marisec, 2006).

The statistics identified above lead to a few observations. The first is the majority of goods being transported globally occurs through ocean transport. Second, the rate of growth in maritime transport is substantial. Third, the relative costs of maritime transport are low, especially when compared to the average cost per item; in our $\$ 700$ television example consisting of roughly $1.5 \%$ of retail cost for the product. From a purely economic standpoint, there seems to be little wrong with maritime shipping. It is a cheap and efficient means of moving goods internationally. This undoubtedly is supporting global trade and lower domestic prices for consumer goods.

Questions of sustainability begin to emerge when one applies full cost/benefit accounting, or a total value approach to maritime shipping. When this is done, serious environmental consequences are shown. For example, the maritime shipping industry is shown to release a greater amount of greenhouse gases than the entire world aviation industry, both commercial and recreational (IMO, 2009). These emissions have been estimated to cause some 60000 premature deaths worldwide every year, as well as substantial health-related monetary impacts (Lack et al., 2009). Beyond the direct and indirect costs of greenhouse gas emissions, which are not included in the direct pricing of maritime shipping, there are other substantial costs related to how ships are handled upon decommissioning. For example, the process of shipbreaking, or the end-of-life decommissioning of a vessel, can result in exposure to hazardous substances like asbestos, as well as oil discharges during the breakdown process (European Commission, 2009). Substantial environmental harm can occur when shipbreaking is done in a jurisdiction with lax environmental standards, or lax enforcement of existing standards.

In many regards, the question of greenhouse gas production through engines used in the maritime industry is one of technology. Advances in technology can bring about reductions through, for example, improvements made to engine efficiencies. Other environmental considerations, such as the danger associated with a ship decommissioning process, can also be dealt with through stringent policies regarding the manner and process of such actions. The point is strong government policies can be readily developed to deal with many of these environmental issues. However, current international practices are resulting in substantial policy failures that are preventing domestic government controls and discouraging progress in international agreements to resolve these environmental problems. Most specifically, the problem of allowing shipowners to register their ships in other jurisdictions with limited environmental regulations is frustrating the implementation and enforcement of environmental regulations. The result is an ever-increasing international maritime shipping industry that remains dirty, unsafe, and engages in environmentally unsound practices for the sake of cost-cutting measures. This 
race-to-the-bottom will do little to lead to sustainable outcomes, especially as we continue to globalize our collective domestic economies. This paper will now explain the open registry system, and how it incentivizes ship owners to register their ships with nations that have the lowest environmental regulations.

\section{Impacts: Domestically Owned - Foreign Flagged}

Today, more than half of the merchant fleet sails under registries of countries that do not require a legal or economic link between the ownership of the vessel and the jurisdiction in which the vessel is registered (UNCTAD, 2009). This has resulted in a handful of countries with limited ability or willingness to adopt or enforce environmental standards holding the registration of the majority of maritime shipping vessels even when actual ownership derives from developed countries (UNCTAD, 2009) (Note 2).

Shipowners from the following developed economies represent $62 \%$ ownership of the global fleet (based on deadweight tonnage). Stark examples of national percentages of domestically owned ships are foreign flagged in developed nations include the following: Japan (92.96\%), Germany (83.39\%), Norway $(77.01 \%)$, Sweden (76.60\%), Switzerland (73.57\%), Greece (68.82\%), Spain (64.88\%), United Kingdom (63.85\%), Denmark (62.15\%), France (54.48\%), Belgium (53.28\%), Netherlands (49.81\%), United States $(48.44 \%)$, and Italy (34.92\%)n contrast, a group of small and weak countries represent the top-ten open registry flags: Panama, Liberia, Marshall Islands, Bahamas, Malta, Cyprus, Isle of Man, Antigua and Barbuda, Bermuda, Saint Vincent and the Grenadines. Alone, these ten countries hold registrations for approximately 55\% of world tonnage (UNCTAD, 2009). So what is the problem with, for example, a citizen-owner in the United States deciding to register their ship in a developing country like the Marshall Islands? The answer begins by analyzing the legal effect of registration, which impacts the environmental costs associated with the registered vessel. A more detailed explanation will be provided below. However, simplistically, the owner of the vessel need not comply with more stringent environmental standards that might exist in their home country. As such, the owner can discount those environmental compliance costs. This discounting allows the owner of the vessel to offer cheaper shipping rates by virtue of passing the savings from non-compliance with environmental standards of the owner's home state. In order to remain competitive, other ship owners will likely be lured into registering their vessels in a jurisdiction with lower environmental standards so they might also discount environmental costs. Nations with low environmental standards might be hesitant to increase environmental compliance requirements because, in doing so, they lose lucrative fees and other benefits associated with registration. In other words, the owners will simply find another country in which to register their vessel.

The effects are also felt by traditional maritime countries in developed countries who feel the pressure to make their fleets more competitive, evidenced by some countries opening dual international registries to let ship owners crew their ships with cheaper labor. In addition, the fear of losing even more ships to foreign flags provides a disincentive for advancement of environmental policies within the maritime industry.

The consequences of this kind of open registration system for sustainability goals can be substantial. At the most basic level of analysis, the current discounting of environmental costs associated with shipping artificially supports demand for global products by reducing overall cost. This allows for wholesale and retail prices to be subsidized through environmental degradation - what some refer to as the taking of natural capital (Note 3). With demand for global products increasing, it is not difficult to see the continued expansion of foreign flagging, especially where doing so allows for a price advantage. With no change in the current system, a race towards foreign flagging can result in a wholly unsustainable practice, where regulatory mechanisms put in place to protect the environment and worker well-being are discounted in the name of short-term profit and cost saving (ITF, 2002). This pattern of unsustainable practice reaches tragic proportions when a ship owner receives top dollar by scrapping their ship on the beaches of a developing country. Such is the case for some $80 \%$ of the world's large ships, sold by ship owners for breaking on tidal flats of developing countries, where migrant workers labor under dangerous conditions that no developed countries would ever accept (European Commission, 2009).

Foreign flagging reinforces patterns of regulatory failure whose impact on the environment. are widening with the expansion of maritime trade. Beyond unsafe working conditions often found in foreign-flagged states, low standard marine diesel fuel is the preferred energy source for commercial vessels (Lack et al., 2009). The sulfur content of this fuel source can average more than 3000 times the amount of fuel used for road transportation. One estimate calculates the world's 15 largest cargo ships have the potential to emit as much sulfur as 760 million cars, the current world total (Vidal, 2009). In addition, the exhaust from marine transport combustion emits as much particulate matter as half of the total number of automobiles on the planet, posing significant health risks that are estimated to cause 60000 worldwide deaths every year (Lack et al., 2009). 
The United States and Canada have already conceded marine shipping is causing a high level of air pollution along coastal areas of North America (United States and Canada, 2009). It is estimated that, if left unabated, marine emission pollutants into the atmosphere will increase over the next twenty years, doubling for nitrogen oxides (NOx), and tripling for particulate matter (PM) (U.S. EPA, 2010). To combat this problem, the United States has laid out a policy of controlling the emissions of domestically-flagged vessels under U.S. law (U.S. EPA, 2009). Of course, this policy only applies to domestically-flagged vessels, and not those that may be owned in the United States by registered with other countries. The U.S. is also attempting to place more stringent controls on domestically-flagged ships that enter U.S. waters, including controls the emission standards of those vessels. (U.S. EPA, 2010; MARAD, 2009). The International Maritime Organization (IMO) approved the North American Emissions Control Area in March, 2009, which will facilitate the ability of the United States and Canada to impose the new standards on foreign-flagged ships. However, the process can serve to underscore the difficulties in setting policies that involve foreign flagged ships, even if many of those ships may be domestically owned.

\section{Outlining Issues to Address}

From a sustainability standpoint, current policies supporting domestically-owned but foreign-flagged shipping must be revisited in its entirety. The main justification for this statement is the current path of environmental discounting will only exacerbate environmental and social harm. Over time, it will become more difficult to reverse these policies of open registries, whose trend has grown steadily with the global dependence on the movement of goods through international maritime shipping. In order to alter this current path towards a more sustainable outcome, the following issues should be considered and addressed. One of the purposes of listing these issues is to prompt research into these areas to identify sustainable policy solutions that meet multiple objectives.

\subsection{The Need to Internalize Environmental Costs}

Any policy solution must address the issue of environmental costs associated with maritime shipping. The clearest way to do this in a competitive free market is to ensure environmental costs are internalized in market transactions (Note 4). There are a number of pathways by which this generalized policy goal can be accomplished. For example, the open registration system can be closed, requiring ownership and flagging of vessels to occur in the same country. Based on the current statistics identified in this paper, such a policy would ensure the vast majority of ship owners would be registered in developed countries. This, in-turn would result in greater internalization of environmental costs because most developed nations have higher environmental standards. Some change would go far in improving the overall environmental quality of maritime shipping in the short-term. However, it is likely owners will find alternative means of identifying ownership and registration to side-step this requirement, especially if the cost-savings is significant. For this reason alone, such a policy may be limited. Still, a viable research direction would be to discern the likelihood of subverting ownership/flag state requirements based on current alternative actions as a comparative study of popular registry nation requirements.

An alternative policy would focus less on the flag state itself (where the ship is registered), and more on the ports of destination (where the ship lands with goods). There are a limited number of nations that represent the majority of destination states for the goods being shipped through maritime transport. These major destination countries could develop stricter requirements for allowing ships into port, including minimum environmental compliance requirements. Ships might also subject themselves to inspection and/or reporting in the port state to ensure environmental compliance measures are being met. Undoubtedly, such actions impact global agreements on trade for member states, and these issues need to be addressed. However, research into the requirements necessary to establish a programmatic port-state environmental compliance policy for the largest consuming countries of maritime trade would go far in helping to offer meaningful policy solutions in this area.

There are numerous other areas of inquiry that can be made in researching and analyzing how environmental costs can be better internalized in global maritime shipping. What will be required to do this effectively includes building a body of academic research founded in case studies that offers insight into how different policy directions can achieve more sustainable outcomes. For example, the U.S. EPA, in determining the detrimental impact of shipping exhaust on U.S. coastal states, will institute a policy targeting the engine emissions of maritime ships (U.S. EPA, 2009). Specifically, U.S. flagged vessels will be regulated to meet ambient air quality standards under the United States Clean Air Act. The United States has also worked to establish bilateral agreements with other countries to control foreign flagged vessels that come to U.S. ports. An excellent case study might be to follow the progression of the U.S. government in establishing the Emissions Control Area, including its efforts to establish international cooperation and coordination, and to see what aspects of this 
process might be expanded to allow for further policies to address the environmental impacts of maritime international trade and to create cooperation amongst sovereign nations. Because of the scale and international scope of this problem, there is ample research to be done to begin deciphering how environmental costs can be rationally internalized to meet internationally recognized agreement on sustainable outcomes.

\subsection{Willingness to Deal with Greater Shipping Costs}

It logically follows that attempts to internalize environmental costs, with all other considerations remaining constant, will likely increase the cost of goods that are shipped through maritime transport. This fact will undoubtedly impact current global trade patterns, which will in-turn impact domestic manufacturing and production, as well as numerous other interests and considerations within the current global economic paradigm. Putting aside potential technological innovations, any suggestion of meeting sustainability goals through internalization of environmental costs will raise questions on the impact on supply-and-demand chains. Any honest answers to the larger questions presented in this paper must include some analysis of how to mitigate the impacts of cost internalization. It is likely this branch of research could benefit from practitioners in the economics and business fields. Identifying mitigation techniques that incorporate principles of sustainability are a critical way of legitimizing any potential policy solution. Further, from an applied standpoint, any policy suggestion that does not reasonably include cost mitigation measures will have little political chance of succeeding, especially in the current economic climate.

Others fields of research that can benefit this area include sociology, psychology, and particularly behavioral science. This suggestion is made because so much of sustainability comes down to questions of choice that include paying for environmental costs today rather than putting payment off until some undetermined time in the future. In the maritime shipping context, one might argue the low cost of goods shipped today is offset by the future costs incurred from climate change mitigation and adaptation strategies (not to mention the attendant medical and social costs). It seems the process of making rational choices between paying today versus tomorrow is based in large part on individual behavioral and group social contexts. Deeper insights into how we might get cultural acceptance of internalizing costs can be quite beneficial when contemplating and drafting policy alternatives.

\subsection{A More Comprehensive Policy Approach to Globalization that Incorporates Sustainable Principles}

As has been suggested, basic principles of sustainability are founded in notions of intergenerational equity under a premise of do no harm. Adapted to the policy setting, any decisions about how governments should act today must account for the ability of future generations to meet their needs. Placing this foundational rule in the context of international maritime shipping, a greater emphasis needs to be placed on sustainability principles as a foundation from which international agreement and cooperation are founded. This suggests a more comprehensive approach to globalization that incorporates sustainable principles as a foundation of policymaking. As mentioned above, there are some specific examples of what nation states are doing to limit the negative environmental impacts of current international maritime shipping practices. However, even these countries sought support from the international community, indicating that unilateral approaches alone are insufficient to engender long-term change in maritime shipping that will lead to sustainable outcomes.

Researchers in international law and policy could significantly aid in the overall development of scholarship, both theoretical and applied, in this area. For example, international agreements have been the foundation for streamlined cooperation amongst nation states. Indeed, the United Nations Convention on the Law of the Sea (UNCLOS) has served as a mechanism for garnering agreement and support for international initiatives with maritime implications. Other international agreements, including the International Convention for the Prevention of Pollution from Ships (MARPOL), offer additional foundations from which sustainable policies relating to maritime trade can be negotiated and implemented.

Maritime law experts can offer insights into the past, present, and future direction of international accords, including how best to imbue the negotiation process with foundational principles of sustainability. It is readily acknowledged this process will not be easy, simply because the current system affords significant environmental discounting, where the profits are currently captured in the form of lower cost of goods and significant rents paid to open registry nations. However, calling attention to the issue through the research community is an important step at moving sustainable policy in a deliberately positive direction.

\section{Conclusion}

The purpose of this paper is two-fold. First, it presents a significant issue for consideration to the members of the academic and research communities related to sustainability; how to deal with the externalization of 
environmental costs in international maritime shipping? In considering this question, this paper has pointed out how the open registry system institutionalizes cost avoidance and prohibits efficient policy solutions. Second, this paper presents a variety of questions and areas of research that might be employed to begin answering the larger issue presented. The fact is international maritime shipping practices are far from sustainable in any reasonable definition of the term. Moreover, these unsustainable practices are only increasing as globalization amplifies the demand for maritime shipping. Alternatives to the current system need to be researched, tested, implemented, and evaluated.

To aid in research and scholarship development, a number of critical policy questions are identified and example directions are offered. By providing a body of both theoretical and applied research, the hope is that relevant government entities will have tools that allow for policy decisions to be made that are imbued with fundamental principles of sustainability. The hope is that the academic community will take up this important task, and we can look towards a brighter future where our continued growth as a global commons will not endanger the prosperity of future generations.

\section{References}

European Commission. (2009). An EU strategy for better ship dismantling (Vol. COM (2008) 767). Communication from the Commission to the European Parliament.

Ehrlich, P. H. (1968). The Population Bomb, Cutchogue, NY: Bucaneer Books, Inc.

Ehrlich, P.H. \& Ehrlich, A.H. (2009). The population bomb revisited. Electronic Journal of Sustainable Development, 1(3). 63-71.

Gladwin, T. N., Kennelley, J.J., \& Krause, T-S. (1995). Shifting paradigms for sustainable development: Implications for management theory and research." Academy of Management Review, 20, 874-907.

ITF. (2002). ITF policy on minimum conditions on merchant ships (From Oslo to Delhi, Chapter 12). Paper presented at the International Trade Federation, 2002 Delhi Congress. Retrieved from http://www.itfglobal.org/files/extranet/-1/451/Delhi\%20Policy.pdf.

IMO. (2009). Second IMO GHG Study 2009 (MEPC 59/4/7). Paper presented at the International Maritime Agency MEPC 59.

Lack, D., Corbett, J., Onasch, T., Lerner, B., Massoli, P., Quinn, P.,...Williams, E. (2009). Particulate emissions from commercial shipping: Chemical, physical, and optical properties. Journal of Geophysical Research, 114, doi: 10.1029/2008JD011300.

MARAD. (2009). U.S. water transportation statistical snapshot. Washington, D.C.: Maritime Administration, U.S. Department of Transportation. Retrieved http://www.marad.dot.gov/documents/US_Water_Transportation_Statistical_snapshot.pdf.

Marisec. (2006). International shipping - carrier of world trade. Maritime International Secretariat Services, Ltd.: Author.

McManus, P. (1996). Contested terrains: politics, stories and discourses of sustainability. Environmental Politics, 5, 48-73.

McGregor, A. (2004). Sustainable development and 'warm fuzzy feelings': Discourse and nature within Australian environmental imaginaries." Geoforum, 35, 593-606.

Millennium Ecosystem Assessment. (2005). Overall Synthesis, Washington, D.C.: World Resources Institute. Retrieved from http://www.marisec.org/worldtradeflyer.pdf.

Naess, A. (2003). The deep ecological movement: Some philosophical aspects (reproduced from Philosophical Inquiry 1986). In A. Light and H. Rolston (Eds.), Environmental Ethics (pp. 262-274). Oxford, UK: Blackwell Publishers Ltd.

UNCTAD. (2009). Review of marine transport 2009 (UNCTAD/RMT/2009). New York, N.Y.: United Nations. Retrieved from http://www.unctad.org/en/docs/rmt2009ch2_en.pdf.

United States and Canada. (2009). Proposal to eesignate an emission control area for nitrogen oxides, sulphur oxides and particulate matter. (MEPC 59/6/5). Retrieved from http://www.epa.gov/otaq/regs/nonroad/marine/ci/mepc-59-eca-proposal.pdf.

U.S. EPA. (2009). Regulatory impact analysis: Control of emissions of air pollution from category 3 marine diesel engines. (EPA-420-R-09-019). Washington, DC: U.S. Environmental Protection Agency. 
U.S. EPA. (2010). Designation of North American emission control area to reduce emissions from ships: Regulatory announcement (EPA-420-F-10-015). Washington, DC: U.S. Environmental Protection Agency.

Vidal, J. (2009, April 9) Health risks in shipping pollution have been 'underestimated.' The Guardian.

WCED. (1987). Our common future: World commission on environment and development. Oxford, UK: Oxford University Press.

\section{Notes}

Note 1. The term established as used in this sentence refers to both informal practices and formalized policy arrangements. The focus of much of this paper is on the formalized (institutionalized) arrangements that lead to unsustainable outcomes. The reason is these kinds of formalized practices are overt impediments to sustainable outcomes. It can be rationally argued that a failure to address institutional arrangements will likely ensure the continuance of the unsustainable policy.

Note 2. At the beginning of 2009, the Review of Maritime Transport published by the United Nations Conference on Trade and Development (UNCTAD, 2009) reported the following findings related to maritime ship ownership and registration:

- Owners from 35 countries controlled $95.6 \%$ of the global merchant fleet of ships over 1000 tons. Of that number, owners from the top five countries controlled slightly more than half $(53.5 \%)$ of the global tonnage: Japan (15.68\%), Greece (15.33\%), Germany (9.50\%), China (8.40\%) and Norway (4.54\%).

- European ownership represented approximately $41.57 \%$ of the global fleet.

- Despite the majority of maritime shipping ownership aggregating in developing countries with stringent environmental standards, the majority of these ships are registered with another country, most of which have substantially diminished environmental standards and/or enforcement of those standards.

Note 3. Natural Capital is the extension of the economic notion of capital to the goods and services relating to the natural environment. Natural Capital can include provisioning services, such as trees for timber or fish for food. It can also include regulating services, such as wetlands to filter water, or the erosion control provided by a stand of trees.

Note 4. One primary assumption in suggesting alternative approaches for internalization of environmental costs is any alternative will be employed within a free market, capitalist enterprise. This assumption conforms to the current path in which globalization, including international maritime shipping, is developing follows neoclassical economic approaches to market economization.

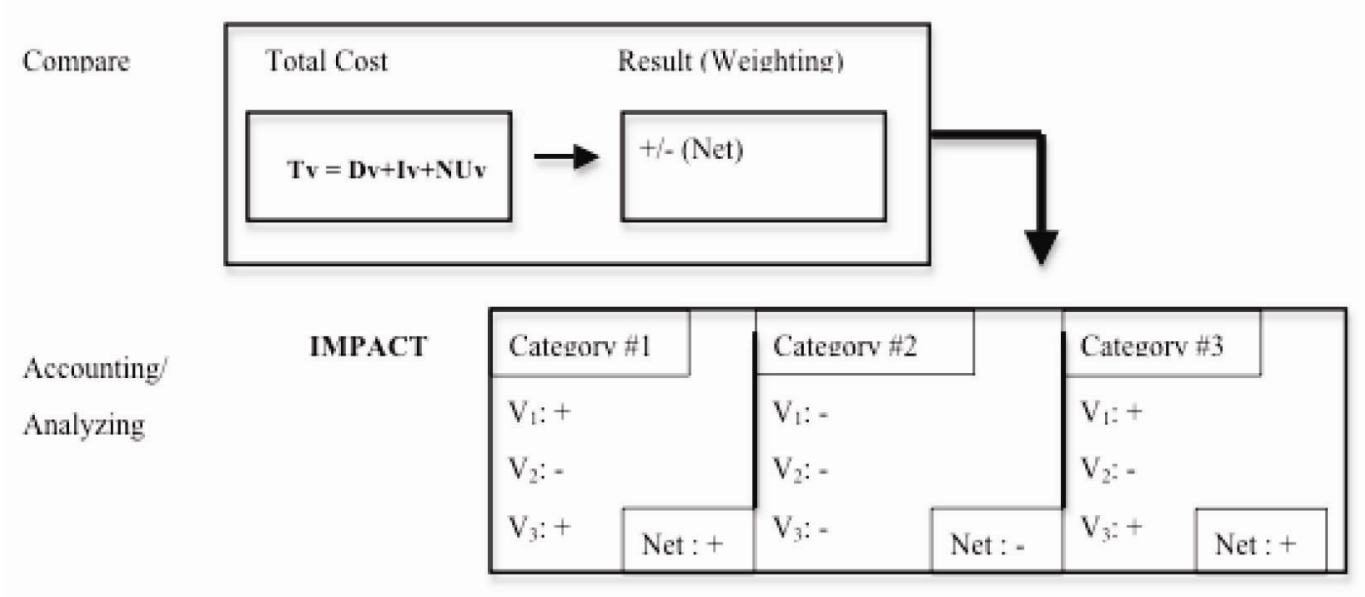

Figure 1. Conceptual Model of Internalization of Environmental Costs

$$
\begin{gathered}
\mathrm{Tv}=\text { Total Value } \\
\mathrm{Dv}=\text { Indirect Value } \\
\mathrm{Iv}=\text { Indirect Value } \\
\mathrm{NUv}=\text { Non-Use Value }
\end{gathered}
$$

